\title{
Michael Graetzel to Give Plenary Address at 2008 MRS Spring Meeting
}

Michael Graetzel of the Ecole Polytechnique Fédérale de Lausanne will give the plenary address at the 2008 Materials Research Society Spring Meeting to be held March 24-28 in San Francisco. The plenary session will be held Monday, March 24, at 7:00 p.m. Graetzel's topic will be "Power from the Sun-The Advent of Mesoscopic Solar Cells."

Graetzel received his $\mathrm{PhD}$ degree from the Technical University Berlin. As a professor at Switzerland's Ecole Polytechnique Fédérale de Lausanne, he directs the Laboratory of Photonics and Interfaces within the Institute of Chemical Science and Engineering Faculty of Basic Science.

In the course of his research, Graetzel has discovered a new type of solar cell

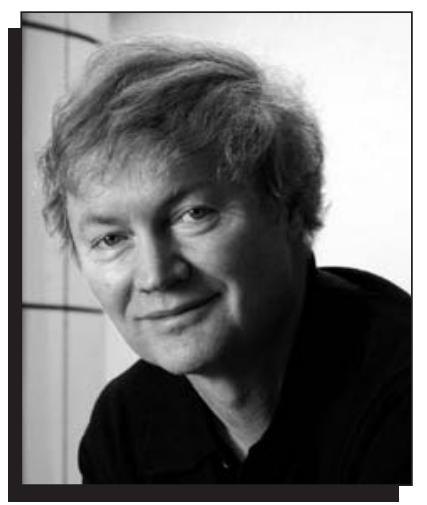

Michael Graetzel

based on dye-sensitized mesoscopic oxide particles, and pioneered the use of nano- materials in energy conversion devices.

Author of over 600 publications, two books, and the inventor of approximately 50 patents, Graetzel ranks amongst the most highly cited scientists in the world. He has received numerous prestigious awards, including the 2007 Harvey Prize, the European Millennium Innovation Award, the ENi-Italgas Prize, the Dutch Havinga Medal, and the Faraday Medal of the British Royal Society of Chemistry. He has also received honorary doctorate degrees from the Universities of Delft, Uppsala, and Turin. He is a member of the Swiss Chemical Society and was elected an honorary member of the Société Vaudoise de Sciences Naturelles.

\section{Michael Strano Named 2008 MRS Outstanding Young Investigator}

Michael Strano, Charles and Hilda Roddey Associate Professor of Chemical Engineering at the Massachusetts Institute of Technology, has been named the 2008 Materials Research Society Outstanding Young Investigator. He is cited for "innovative work on single walled carbon nanotube chemical modifications, both fundamental and applied, and for pioneering a new class of near infrared sensor architectures based upon chemically induced optical modulation of carbon nanotubes." He will deliver an award talk at the Materials Research Society Spring Meeting in San Francisco.

Strano and his group have shown that it is possible to construct a new class of near infrared, nanotube-based optical sensors from single-walled carbon nanotubes, by decorating the surface with biorecognition ligands, and connecting the binding at the ligand with ferricyanide mediator chemistry. By controlling the shuttling of electrons in and out of nanotube systems, Strano's research group has created novel electronic and optical devices. For example, his group has fabricated and demonstrated an $\mathrm{Hg} 2+$ ion sensor, capable of near infrared query

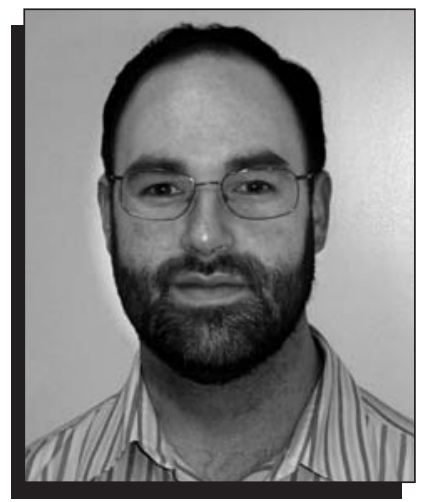

Michael Strano

from within living cells. They have also used DNA-decorated single-walled nanotubes as a platform to observe unique molecular transformations in the DNA while adsorbed to the nanotube.

Although best known internationally for his advances in the applications field, Strano has pioneered the study of fundamental mechanisms of carbon nanotube chemistry. His group has developed a chemical method to separate and sort single-walled carbon nanotubes by their electronic structure, an important goal in the field of nanotube research.

Strano received his $\mathrm{PhD}$ degree in chemical engineering from the University of Delaware, Newark in 2001. Following a postdoctoral year at Rice University in Houston, he spent four years at the University of Illinois, Urbana-Champagne as assistant professor (2003-2006) and associate professor (2006-2007) before his current appointments at MIT. His many honors include the DuPont Young Innovator Award (2004), the Coblenz Award for Excellence in Molecular Spectroscopy (2006), and the American Chemical Society Unilever Award for Collisional Science (2007). Strano was appointed to the National Academy of Engineers Frontiers of Engineering in 2007.

$\mathrm{He}$ is a member of the American Chemical Society, the American Physical Society, the Materials Research Society, and the American Institute of Chemical Engineers. He has more than 70 journal publications, and in 2005, the Essential Science Indicators Web of Science listed him in the top $1 \%$ of highly cited researchers. Strano has published five book chapters and has been granted eight U.S. patents.

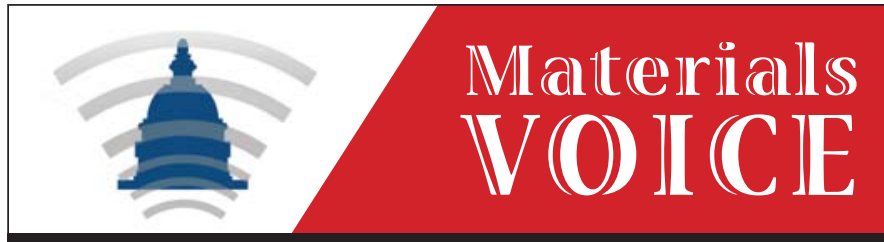

A Web-based tool to ensure that your voice is heard on Capitol Hill www.mrs.org/materialsvoice

Visit the Materials Voice kiosk at the 2008 MRS Spring Meeting in San Francisco! 


\section{MRS Invites Nominations for the Von Hippel Award, Turnbull Lectureship, and MRS Medal}

The Materials Research Society is seeking nominations for the Von Hippel Award, the Turnbull Lectureship, and the MRS Medal. The deadline for nominations is April 1, 2008. These awards will be presented at the 2008 MRS Fall Meeting, December 1-5, in Boston.

The MRS awards program recognizes outstanding contributors to the progress of materials research. Nomination forms and details about eligibility and nomination criteria are available from the Materials Research Society Web site at www. mrs.org/awards.

\section{Von Hippel Award Acknowledges Outstanding Interdisciplinary Work in Materials Research}

The Von Hippel Award, first presented to Arthur R. von Hippel, whose interdisciplinary and pioneering research typified the spirit of the award, is the Society's highest honor. The recipient is recognized for brilliance and originality of intellect, combined with vision that transcends the boundaries of conventional scientific disciplines. The award includes a $\$ 10,000$ cash prize, honorary membership in MRS, and a unique trophy - a mounted ruby laser crystal, symbolizing the manyfaceted nature of materials research.

\section{Turnbull Lectureship Honors Career of an Outstanding Researcher and Communicator}

The David Turnbull Lectureship recognizes the career of a scientist who has made outstanding contributions to understanding materials phenomena and properties through research, writing, and lecturing, as exemplified by the life work of David Turnbull. While honoring the accomplishments of the recipient, the Turnbull Lectureship is intended to support and enrich the materials research community.
The recipient will give a technical lecture of broad appeal at a designated session of the 2008 MRS Fall Meeting. The Turnbull Lecturer will receive a $\$ 5,000$ honorarium and a citation plaque, along with a travel allowance for speaking engagements throughout the year.

\section{MRS Medal Recognizes Recent Discovery or Advancement in Materials Science}

The MRS Medal offers public and professional recognition of an exceptional achievement by an individual in materials research. The Medal is awarded for a specific outstanding recent discovery (approximately last 10 years) or advancement that is expected to have a major impact on the progress of any materialsrelated field.

The award consists of a $\$ 5,000$ cash prize, an engraved and mounted medal, and a citation certificate.

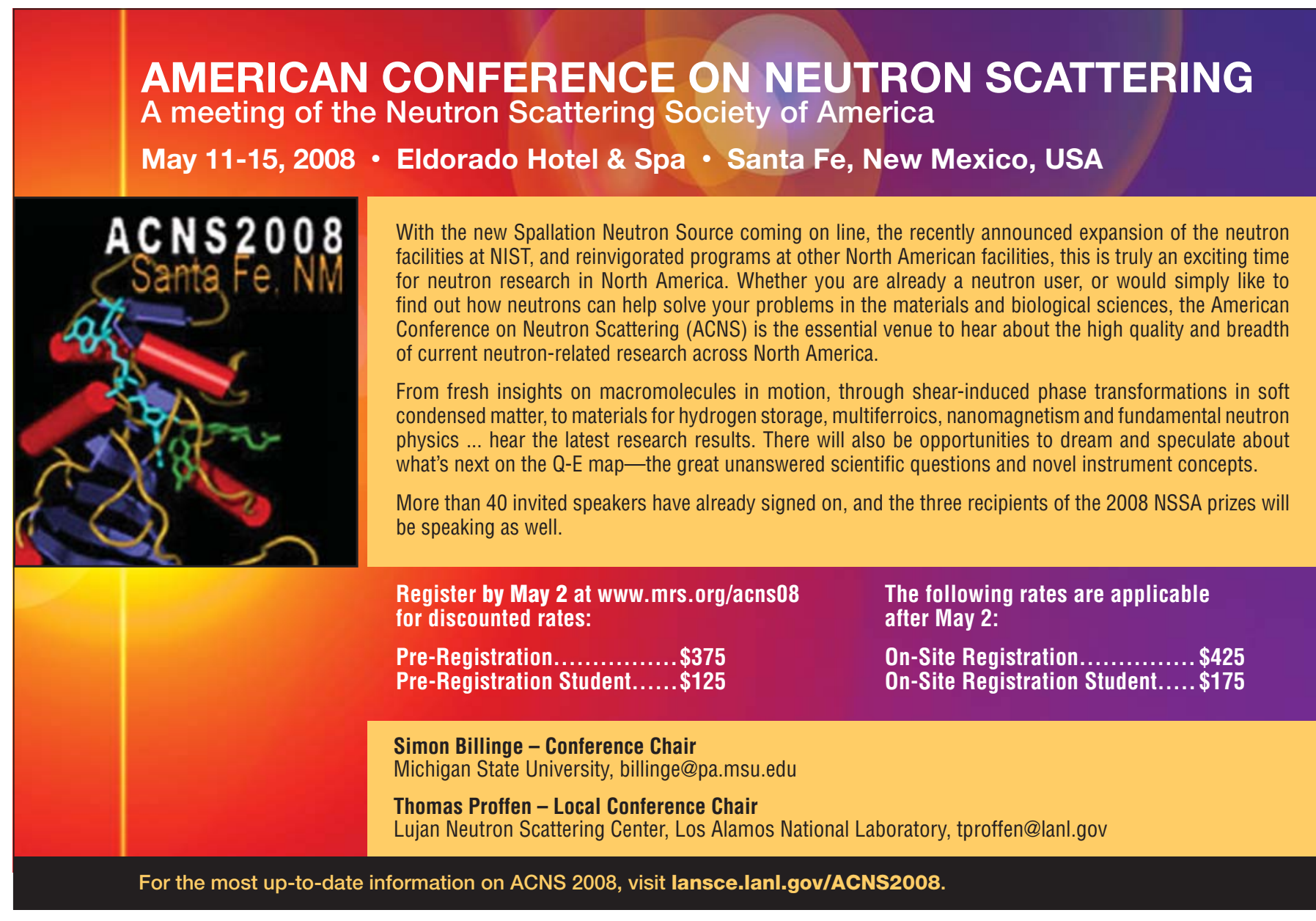

